\title{
ACESSIBILIDADE ESPACIAL PARA IDOSOS EM ZONAS TURÍSTICAS BALNEARES COSTEIRAS: ESTUDO DE CASO EM BALNEÁRIO CAMBORIÚ/SC
}

\section{SPATIAL ACCESSIBILITY FOR ELDERY IN TOURIST BALNEARS: CASE STUDY IN BALNEÁRIO CAMBORIU/SC}

Franciele Fantini ${ }^{1}$, MsC

Marta Dischinger ${ }^{2}, \mathrm{PhD}$

(1) Universidade do Vale do Itajaí (UNIVALI)

e-mail:franfantini@gmail.com

(2) Universidade Federal de Santa Catarina (UFSC)

e-mail: martadischinger@gmail.com

Palavras-chave: acessibilidade, idosos, zonas balneares.

Este trabalho, baseado na dissertação de mestrado da autora [revisão cega] orientada por [revisão cega], tem como finalidade analisar, a partir de um estudo de caso, as barreiras encontradas em uma zona balnear costeira. Após levantamento in loco, propõem-se soluções gerais para tornar este espaço acessivel espacialmente à gama de usuários que o frequenta.

\section{Key-words: Accessibility, Eldery, Balnears}

This work, based on the author's dissertation, aims to analyze, based on a case study, the barriers encountered in a tourist balnear. After site visits, we propose general solutions to make this area spatial accessible to the range of users who frequents it.

\section{Introdução}

O envelhecimento populacional representa uma vitória da humanidade ao mesmo tempo em que traz consigo uma série de demandas e desafios.
Na perspectiva do envelhecimento ativo, o convívio social, fundamental para o ser humano, assume uma grande importância para os indivíduos idosos, prevenindo a solidão e o isolamento, tão comuns após a aposentadoria (DIOGO, 1999). Esse convívio freqüentemente se dá em forma de lazer, o qual assume, nos dias atuais, um caráter 


\section{$16^{\circ}$ \\ ERGODESIGN USIHC CINAHPA}

$16^{\circ}$ Ergodesign - Congresso Internacional de Ergonomia e Usabilidade de Interfaces Humano Tecnológica: Produto, Informações Ambientes Construídos e Transporte

$16^{\circ}$ USIHC - Congresso Internacional de Ergonomia e Usabilidade de Interfaces Humano Computador

CINAHPA | 2017 - Congresso Internacional de Ambientes Hipermídia para Aprendizagem. essencial frente à busca pela melhoria na qualidade de vida.

Dentre as modalidades de lazer, o turismo é uma das mais praticadas atualmente, por aqueles que possuem autonomia, tempo livre e condições

financeiras. O direito de todos os indivíduos ao turismo é assegurado no Artigo $2^{\circ}$ do Código de Ética Mundial do Turismo (WTO,1999), o qual ressalta o seu papel como meio de desenvolvimento pessoal e coletivo, além de promotor dos direitos humanos em grupos populacionais mais vulneráveis.

Ao mesmo tempo em que o turismo para a Terceira Idade, enquanto manifestação cultural e psicossocial é um importante instrumento de inclusão do idoso, permitindo-lhe uma participação mais efetiva na sociedade (FROMER; VIEIRA, 2003), o aumento das viagens realizadas por este grupo etário não gerou, na prática, muitos locais que ofereçam condições para que todos possam usufruir do turismo de lazer. Frequientemente a participação voluntária e autônoma de pessoas idosas em determinadas vivências de lazer e turismo, como em zonas balneares, é limitada e/ou inibida por fatores como a falta de infra-estrutura e acessibilidade espacial do destino escolhido. Segundo Dischinger, Bins Ely e Piardi (2011), "acessibilidade significa bem mais do que poder atingir um lugar desejado". Segundo as autoras, um espaço acessível é aquele de fácil compreensão, que permite ao usuário comunicarse, ir e vir, assim como participar de todas as atividades com segurança, conforto e autonomia. Para que os espaços sejam acessíveis, deve-se considerar os quatro componentes da acessibilidade: orientação/informação, deslocamento, uso e comunicação, elaborados por Dischinger e Bins Ely(2006).

Orientação e informação estão relacionadas com a compreensão dos ambientes, baseado em informações como as visuais,sonoras e arquitetônicas. Já o deslocamento refere-se às condições de movimento e livre fluxo das áreas de circulações, devendo ser considerado tanto verticais quanto horizontais.

O componente uso, por sua vez, está relacionado com a participação em atividades e utilização de equipamentos, mobiliários e objetos. A comunicação, por fim, está ligada à facilidade de interação entre os usuários e destes com o ambiente, garantida por configurações espaciais ou tecnologias assistivas.

Diante destes conceitos verifica-se que, no caso do Brasil, apesar de seu inegável potencial para a atividade turística pelo seu expressivo acervo de bens paisagísticos, naturais, culturais e sociais, ainda não se alcançou condições ideais, sustentáveis e inclusivas de modo a permitir o acesso de todos à experiência turística, principalmente quando se trata do turismo de Praia e Sol, um de nossos grandes atrativos.

Dessa forma, um estudo envolvendo acessibilidade espacial e Desenho Universal em zonas turísticas balneares costeiras mostra-se de relevância significativa, uma vez que parte dos famosos destinos turísticos do País está relacionada a essas zonas balneares as quais, em sua maioria, não possuem espaços acessíveis espacialmente ou somente projetos pontuais para soluções temporárias.

Somam-se a isso, dois fatores: o envelhecimento da população brasileira com uma porcentagem significativa de deficientes em relação ao total de habitantes, e que constituem público potencial para atividades de turismo e a legislação e normas em vigência que tratam a respeito de acessibilidade espacial serem pouco específicas face à grande variedade de usuários e atividades exercidas em zonas balneares, o que reforça a necessidade de estudos que venham a contribuir para o seu detalhamento e aperfeiçoamento.

\section{Métodos e Técnicas}

Com o intuito de tornar possível um conhecimento e avaliação mais aprofundada em relação ao tema, assim como conhecer de que forma o usuário percebe seu entorno, desempenha suas atividades e como o espaço poderia estar configurado para ser acessível espacialmente, de modo a poder elaborar diretrizes projetuais, optou-se por seguir as seguintes etapas: 1) Revisão teórica-documental, 2) Levantamento técnico, 3) Entrevistas, 4) Passeio acompanhado e 5) Projeto-piloto.

Como forma de organização deste trabalho optouse por fragmentar os procedimentos em grupos denominados de: Aprendendo sobre o tema $\left(1^{\mathrm{a}}\right.$
Realização:

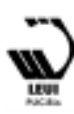




\section{$16^{\circ}$ \\ ERGODESIGN USIHC CINAHPA}

etapa), Aprendendo sobre o local ( $2^{\mathrm{a}}$ etapa), Aprendendo sobre usuário, o problema e suas resoluções ( $3^{\mathrm{a}}$ etapa até $5^{\mathrm{a}}$ etapa).

Para aprender sobre o tema, fez-se uma revisão bibliográfica, para se compreender e aprofundar referenciais teóricos relacionados aos seguintes conceitos: o lazer e o direito de todo cidadão ao seu acesso, o turismo como forma de lazer e os espaços destinados a sua realização, a

acessibilidade espacial como meio para permitir a todos o usufruir dos espaços e atividades de lazer e, por fim, os idosos como público-alvo para realização deste tipo de atividade no espaço escolhido para a pesquisa.

O estudo de caso foi o método escolhido para ampliar o conhecimento do fenômeno estudado. Para a investigação sobre o local, optou-se por realizar um levantamento técnico na orla principal de Balneário Camboriú/SC.

Após o reconhecimento da orla foi elaborada a análise da organização espacial e funcional do calçadão e praia, assim como a avaliação do uso e estado de conservação dos equipamentos e dos mobiliários existentes.

Essa análise baseou-se em levantamentos métricos e registros fotográficos. Com a finalização desta etapa, verificou-se que o levantamento técnico realizado seria suficiente para se conhecer o espaço escolhido para o estudo, todavia insuficiente para avaliar a relação entre o usuário e este espaço. Assim, para aprender sobre o usuário, foram escolhidos os instrumentos: entrevistas semiestruturadas e abertas (QUIVY;CAMPENHOUDT, 2003) na baixa e alta temporada do Turismo de idosos, observações diretas

(QUIVY;CAMPENHOUDT, 2003) e passeio acompanhado (DISCHINGER, 2000).

Por fim, objetivando um maior aprofundamento no problema e em suas resoluções e baseado na experiência prática das autoras com projetos arquitetônicos e urbanísticos, optou-se por utilizar o espaço do estudo de caso para realização de um projeto-piloto, a nível de estudo preliminar, para que se pudesse aplicar o conhecimento obtido na teoria e, através do projeto, se pudesse elaborar diretrizes a serem aplicadas em futuros projetos. Este processo é denominado por Schön (1987) de reflection-in-action ou reflexão-na-ação.

Essa etapa teve o intituito de auxiliar a elaboração $16^{\circ}$ Ergodesign - Congresso Internacional de Ergonomia e Usabilidade de Interfaces Humano Tecnológica: Produto, Informações Ambientes Construídos e Transporte

$16^{\circ}$ USIHC - Congresso Internacional de Ergonomia e Usabilidade de Interfaces Humano Computador

CINAHPA | 2017 - Congresso Internacional de Ambientes Hipermídia para Aprendizagem.

das diretrizes projetuais baseadas nas possíveis lacunas existentes entre a norma e o projeto, as quais poderão ser aplicadas em outros casos, sempre com análise criteriosa e adaptação para as condições de cada espaço e necessidades de seus usuários.

\section{Aprendendo sobre o local}

Balneário Camboriú situa-se na microrregião de Itajaí, a 80 km da capital Florianópolis, Santa Catarina.

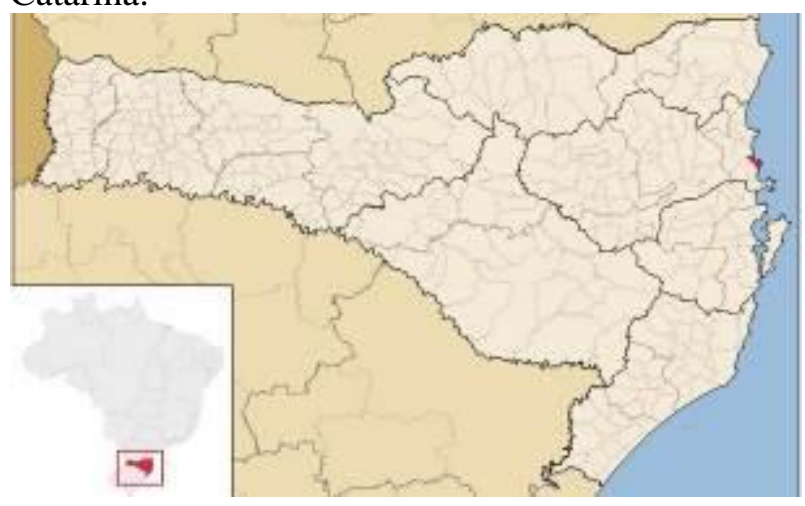

Imagem 01. Mapa Brasil, Santa Catarina e Balneário Camboriu - localização. Fonte: Wikipedia, 2013.

O município possui três modalidades de acesso: terrestre, aéreo e marítmo, com destaque para a BR-101, os aeroportos de Navegantes (SC) e de Florianópolis (SC) e o Porto de Itajaí. O turismo é a principal atividade econômica, seguido pela indústria e agropecuária, que são inexpressivas neste contexto. No período de dezembro a março, o município é o destino de muitos turistas, oriundos do Paraná, de Santa Catarina, do Rio Grande do Sul, de São Paulo e Goiás, assim como de outros países: Argentina, Paraguai, Chile, França e Portugal. 


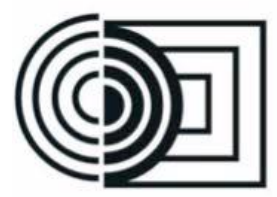

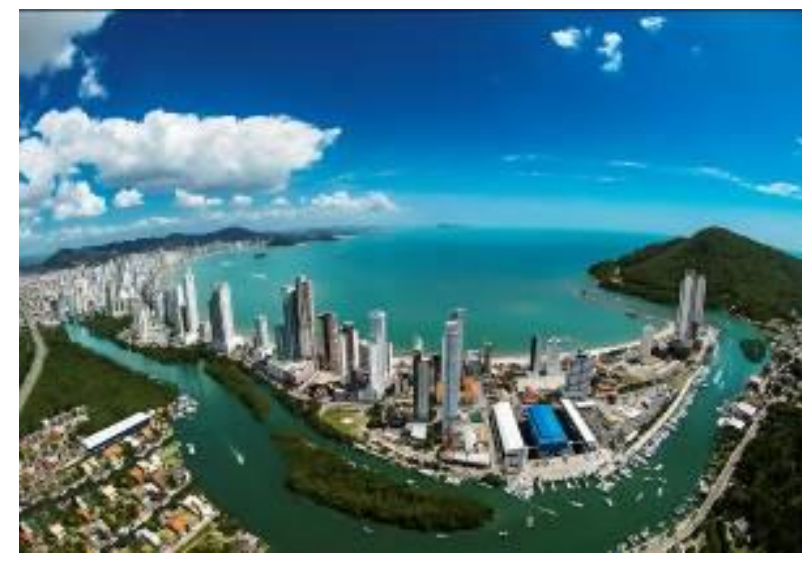

Imagem 02. Praia Central e canal da marina Tedesco.

Fonte: http://neog1.com.br/blog/wpcontent/uploads/2015/11/neoblog091101.jpg

Trata-se de um centro de estada no qual o sol, a praia e o mar são os maiores atrativos durante a temporada. Todavia, após o término da mesma percebe-se a mudança de um público jovem para um público idoso, assim como maior usufruto da cidade por aqueles que fogem da agitação durante a temporada.

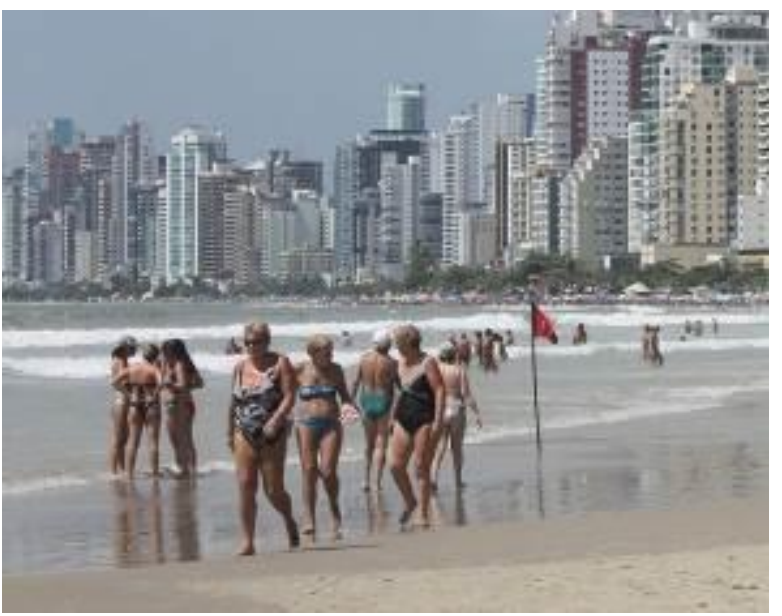

Imagem 03. Idosos na praia central. Fonte: Acervo Próprio, 2012

Segundo a SANTUR, Balneário Camboriú lidera a preferência deste segmento populacional no Estado, recebendo entre março e maio, cerca de 500 mil visitantes. Outro forte sinal da presença de visitantes idosos no município está na pesquisa de demanda turística da Secretaria de Turismo e Desenvolvimento Econômico do Município (SECTUR), referente a março de 2012, que $16^{\circ}$ Ergodesign - Congresso Internacional de Ergonomia e Usabilidade de Interfaces Humano Tecnológica: Produto, Informações Ambientes Construídos e Transporte

$16^{\circ}$ USIHC - Congresso Internacional de Ergonomia e Usabilidade de Interfaces Humano Computador

CINAHPA | 2017 - Congresso Internacional de Ambientes Hipermídia para Aprendizagem. apresenta $30,37 \%$ de turistas na cidade na faixa etária entre 51 e 65 anos.

Diante deste cenário, foi escolhida a Praia Central da cidade como recorte de estudo face à grande concentração de atividades do turismo, principal atividade econômica da cidade, assim como a presença significativa de equipamentos e áreas de lazer que tornam este local intensamente frequentado tanto pela a população permanente quanto pelos turistas. Essa zona balnear apresentase, dessa forma, como a imagem pública de Balneário Camboriú diante dos principais mercados emissores.

\section{Aprendendo sobre o usuário}

A orla da praia Central de Balneário Camboriú é um espaço público frequentado por usuários de todas as faixas etárias, moradores, turistas nacionais e internacionais.

Tratando-se do usuário idoso, foco do estudo, verificou-se tanto nas entrevistas realizadas em época considerada baixa temporada para o turismo da Terceira Idade na cidade (novembro-março), quanto na alta temporada (março-maio) que a maior parte possuíram de 60 a 70 anos, mas chamou a atenção a porcentagem de idosos acima dos 81 anos, principalmente com o intuito de uso do espaço para melhoria da qualidade de vida. Na baixa temporada, a maior parte dos entrevistados idosos era morador da cidade e a menor turista, ao contrário da alta temporada. Os visitantes frequentes são comuns, principalmente moradores das cidades vizinhas que utilizam Balneário Camboriú como zona balnear e de descanso nos finais de semana.

Nas entrevistas realizadas na baixa temporada, verificou-se que a maioria dos entrevistados frequenta a orla durante todo o ano, seguidos pelos que frequentam de março a maio.

Já nos resultados obtidos na alta temporada, boa parte dos entrevistados afirmou que visitava apenas na alta temporada deste turismo, reforçando o caráter significativo deste fluxo após a temporada convencional de verão.

Em ambas as etapas de entrevistas boa parte dos idosos que responderam ao questionário afirmaram 


\section{$16^{\circ}$ \\ ERGODESIGN USIHC CINAHPA}

que frequentam a orla pela manhã, seguidos do período vespertino. O período matutino se destaca principalmente pela presença do sol no calçadão, $o$ qual acaba sombreado a partir do meio da tarde devido ao elevado gabarito das edificações que bordeiam a Avenida Atlântica.

Em ambas as etapas a maior parte dos entrevistados frequenta somente o calçadão e além da atividade realizada não condizer com a areia, outro motivo apontado pela maioria dos entrevistados estava relacionada à acessibilidade espacial.

\section{Aprendendo sobre problema e suas resoluções}

A partir das etapas anteriores foram levantadas as principais atividades realizadas por este público na zona balnear escolhida, suas dificuldades e facilidades de realização.

Dentre as atividades destacam-se as físicas, juntamente com as sociais, principalmente àquelas características destes espaços, como o banho de sol e mar, as caminhadas e os encontros.

\subsection{Atividades realizadas}

Para chegar da cidade até a orla, de acordo com as entrevistas e observações sistematicas, o usuário utiliza como meios principais: o transporte público, particular, bicicletas e a pé.

Dentre os espaços existentes na orla de Balneário Camboriú o calçadão é aquele mais utilizado durante todo o ano, seja por moradores ou turistas. Durante as observações, identificaram-se 14 atividades realizadas por idosos na área: caminhada, corrida, andar de bicicleta, fazer alongamentos, passear com animal de estimação, tomar banho de sol, contemplar a paisagem, ler, fazer trabalhos manuais, usar o computador/tablet, encontrar familiares e amigos, jogar dominó ou cartas, jogar bocha, fazer refeições e lanches. Além do uso do calçadão, outra atividade realizada é o uso da zona balnear propriamente dita para caminhadas, banho de sol e mar. De modo complementar à todas estas atividades, tem-se o uso de duchas e banheiros. $16^{\circ}$ Ergodesign - Congresso Internacional de Ergonomia e Usabilidade de Interfaces Humano Tecnológica: Produto, Informações Ambientes Construídos e Transporte

$16^{\circ}$ USIHC - Congresso Internacional de Ergonomia e Usabilidade de Interfaces Humano Computador

CINAHPA | 2017 - Congresso Internacional de Ambientes Hipermídia para Aprendizagem.
Neste artigo serão analisadas as atividades realizadas pelos usuários a partir do acesso entre calçadão e praia, o desfrutar do uso da zona balnear, assim como dos banheiros e duchas. A seguir, serão pontuados os problemas e as diretrizes para soluções, de modo a minimizar ou eliminar as barreiras existentes, sempre com o foco na questão: quais as maiores dificuldades, em cada atividade, que o usuário enfrenta para conseguir se orientar, deslocar, usar e se comunicar neste espaço urbano?

\subsection{Acesso entre calçadão e faixa de areia}

Um dos aspectos mais críticos verificados durante o levantamento técnico foi aquele que tange o acesso entre calçadão e praia. Na maior parte da orla, a faixa de areia encontra-se até um metro abaixo do nível do calçadão. Para vencer este desnível, foram adotadas soluções como: degraus formais, degraus informais ou ainda rampas. Pra transpor este desnível, usuários contam com escadas e rampas construídas pela Prefeitura Municipal e patamares e degraus construídos informalmente.

No acesso por escadas formais, a principal dificuldade encontrada para orientação e comunicação foi o fato de as mesmas não possuírem distribuição homogênea tampouco marcação ou sinalização tátil para localização dos acessos.

Já em relação ao deslocamento e uso, verificou-se que as bases e espelhos em grande parte das escadas não possuem dimensionamento adequado e as larguras não são padronizadas. Além disso, o piso utilizado o cimento bruto que, juntamente com a areia deslocada da praia ou água que escorre das duchas, torna-se derrapante. De uma forma geral, as escadas não possuem corrimão e faixas para demarcação dos degraus, dificultando o uso. 


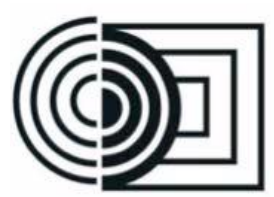

$16^{\circ}$ Ergodesign - Congresso Internacional de Ergonomia e Usabilidade de Interfaces Humano Tecnológica: Produto, Informações Ambientes Construídos e Transporte

$16^{\circ}$ USIHC - Congresso Internacional de Ergonomia e Usabilidade de Interfaces Humano Computador

CINAHPA | 2017 - Congresso Internacional de Ambientes Hipermídia para Aprendizagem.

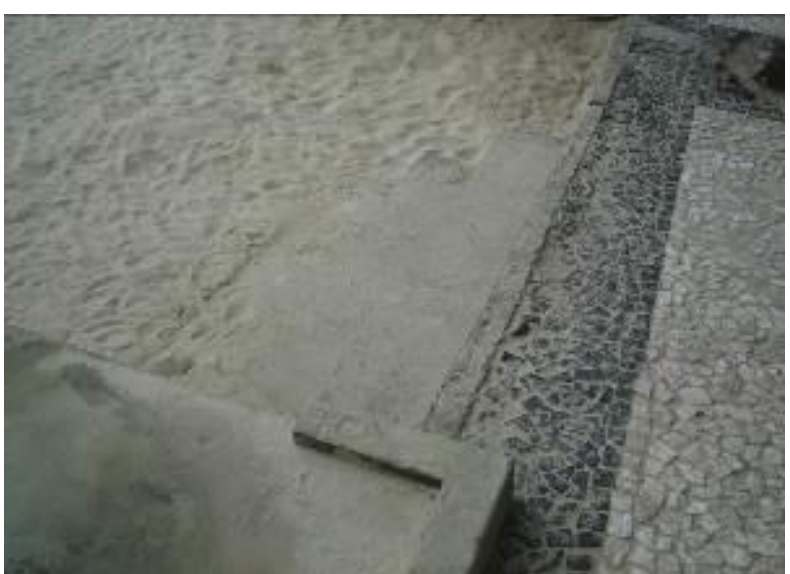

Imagem 04. Acesso formal no local de Estudo de caso. Fonte Acervo Próprio, 2013

Os problemas nas escadas informais se repetem igualmente, somados ao fato de que a maior parte delas foram feitas de pedaços de madeira ou ainda pallets, com problemas de falta de rigidez e rebarbas que podem levar a um tropeço ou até queda.

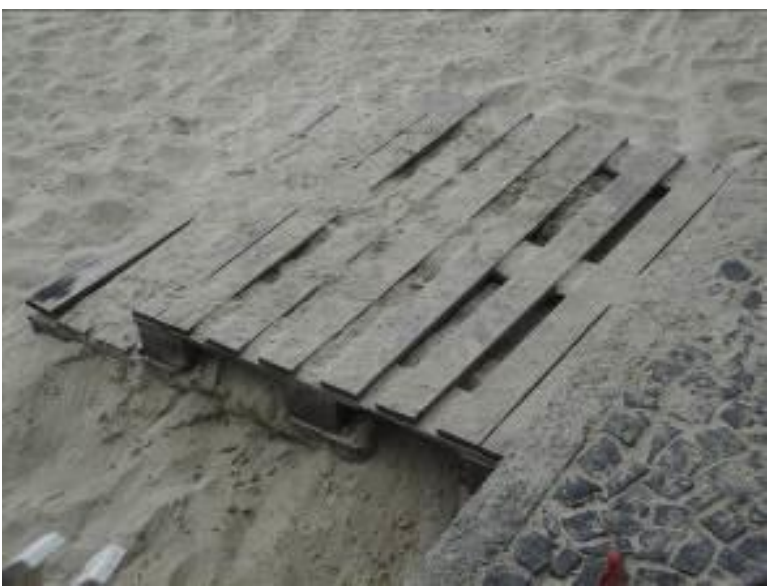

Imagem 05. Acesso informal no local de Estudo de caso. Fonte Acervo Próprio, 2013

As rampas, por sua vez, também não possuem distribuição homogênea e marcação ou sinalização tátil para localizar seus acessos.

Os demais problemas verificados estão

relacionados aos componentes uso e deslocamento, destacando-se: rampas que possuíam desde 15 a $38 \%$ de inclinação, assim como larguras que vão desde $80 \mathrm{~cm}$ até $150 \mathrm{~cm}$ sem relação direta com o fluxo existente no local; inexistência de corrimão, sinalização tátil e guias de balizamento na altura adequada. A inclinação transversal de $3 \%$ estabelecida pela norma é atendida na maior parte das rampas verificadas e, quando não atendida, ainda é inferior a $4 \%$.

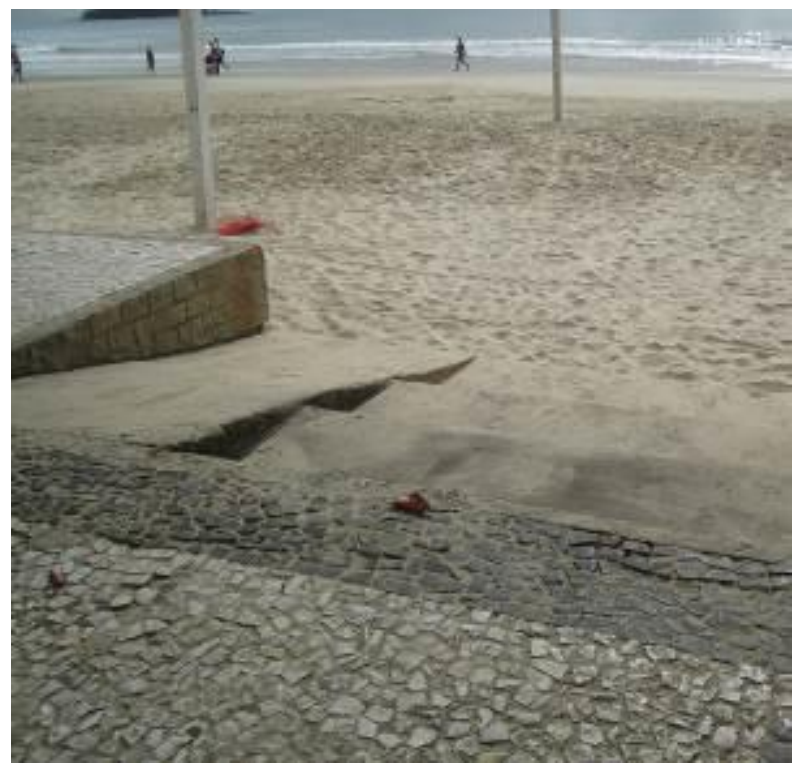

Imagem 06. Rampa e escada do acesso formal no local de Estudo de caso. Fonte Acervo Próprio, 2013

Para solucionar o desnível existente entre a faixa de areia e o calçadão, recomendam-se acessos por rampas e escadas com soluções baseadas na NBR9050/2015.

Com o intuito de melhorar a orientação dos usuários do espaço, sugere-se o uso de suporte informativo tátil - piso alerta e direcional indicando a partir da rota acessível até a praia, assim como início e término das rampas e escadas. Além disso, faixas antiderrapantes de cor contrastante devem ser instaladas no fim de cada degrau, para tornar o uso mais seguro, a partir do momento que o idoso e/ou pessoa com baixa visão consegue identificar com maior facilidade o limite do desnível.

Quando não houver barreiras laterais, deve-se prever guarda corpo com $105 \mathrm{~cm}$ de altura e guia de balizamento, para maior segurança do usuário diante do desnível gerado pela subida.

Para permitir o deslocamento autônomo e confortável, o piso do acesso deve ser estável, antiderrapante, regular e anti-reflexo em qualquer
Realização:
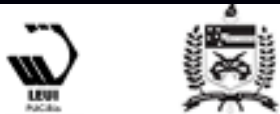


\section{$16^{\circ}$ \\ ERGODESIGN USIHC CINAHPA}

condição e as escadas e rampas devem possuir dimensões compatíveis para atender o grande fluxo de turistas durante a temporada, sempre prevendo patamares desobstuídos, no início e no fim do percurso.

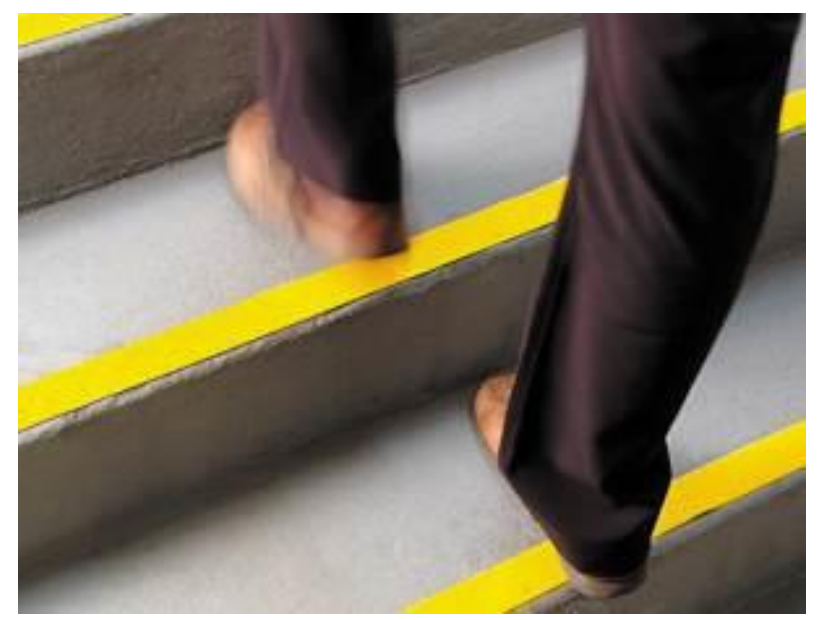

Imagem 07. Faixa antiderrapante com contraste de cor em relação ao piso. Fonte:

http://www.solucoesindustriais.com.br/images/produtos/ imagens_10050/p_faixa-de-sinalizacao-visual-paradegraus-de-escada-21.jpg

Em caso de rampas extensas, deve-se prever patamares intermediários para descanso, já que com o decorrer da idade é comum a perda do tônus muscular e a fadiga torna-se mais frequente mesmo durante exercícios breves.

A inclinação da rampa de acesso, por sua vez, deve estar 6,25 e 8,33\% para desníveis de até $80 \mathrm{~cm}-$ maior parte das situações encontradas - e menos de $2 \%$ de inclinação transversal.

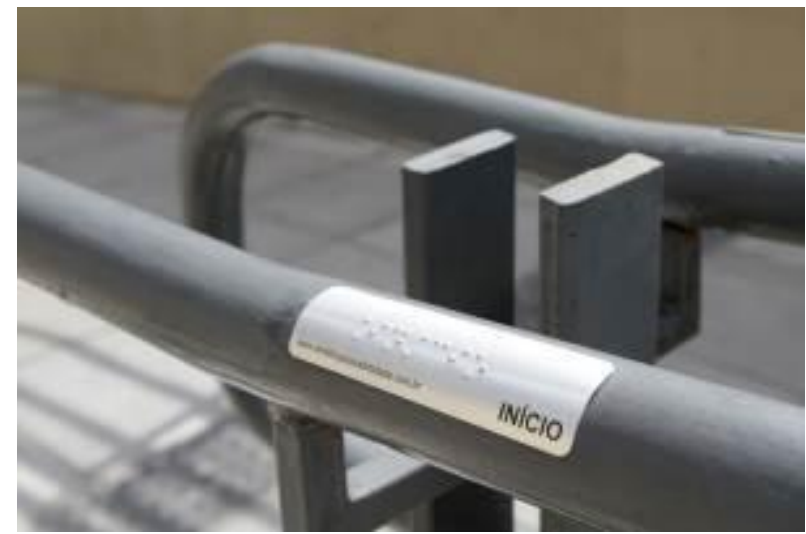

Imagem 08. Informação tátil no corrimão. Fonte $16^{\circ}$ Ergodesign - Congresso Internacional de Ergonomia e Usabilidade de Interfaces Humano Tecnológica: Produto, Informações Ambientes Construídos e Transporte

$16^{\circ}$ USIHC - Congresso Internacional de Ergonomia e Usabilidade de Interfaces Humano Computador

CINAHPA | 2017 - Congresso Internacional de Ambientes Hipermídia para Aprendizagem. http://www.anhembi.com.br/wpcontent/uploads/Acessibilidade_180113_Foto_JoseCord eiro_0063.jpg

Em relação ao uso, segundo a norma os corrimãos tanto das escadas quanto das rampas, devem possuir duas alturas $(70$ e $92 \mathrm{~cm})$, sem arestas vivas, com $4 \mathrm{~cm}$ de largura e instalados unilateralmente, sempre avançando $30 \mathrm{~cm}$ antes do início e após o final do percurso.

Sempre que possível utilizar sinalização em Braille nos corrimãos com informações relevantes a respeito do espaço para orientação dos que possuem baixa visão ou cegueira.

Em relação ao dimensiomanento x fluxo, circulações amplas (acima de 1,80 m de largura) permitem idosos, cadeirantes e pequenos grupos caminharem lado a lado. Caso não seja possível construir estrutura com esta dimensão, a norma recomenda adotar no mínimo $1,50 \mathrm{~m}$, sendo o mínimo admissível de 1,20 m.

Para melhor orientação do usuário, a iluminação deve ser distribuída homogeneamente no decorrer dos passeios, sendo mais alta para a iluminação geral e mais baixa para iluminação de caminhos e áreas destinadas à atividades específicas. Pode-se também aproveitar as guias de balizamento para embutir iluminação, de modo a favorecer o deslocamento, assim como tornar mais visíveis os limites do caminho.

Por fim, cabe ressaltar que diferente do Estudo de Caso, podem ocorrer situações onde a transição entre a cidade e a praia ocorra através de uma zona com restinga e/ou área de preservação, com a possibilidade de haver desníveis acentuados. Nessas situações recomenda-se a instalação de trilhas acessíveis, através de passarelas elevadas, as quais não serão exploradas neste artigo.

\subsection{Uso da praia}

Quando vencida a barreira de acesso entre o calçadão e a faixa de areia, tem-se ampliadas as dificuldades de acesso ao se chegar no espaço de areia.

$\mathrm{O}$ primeiro e mais notável item referente às dificuldades se relaciona ao deslocamento dos 


\section{$16^{\circ}$ \\ ERGODESIGN USIHC CINAHPA}

usuários. Não há nenhum tipo de piso diferenciado que configure rota acessível. Soma-se, ainda, à esta dificuldade o fato da elevada densidade de ocupação, que faz com que os frequientadores da praia tenham que buscar pequenas brechas para chegar ao destino pretendido, inviabilizando ainda mais o acesso de todos.

Em relação ao uso, em nenhum trecho da orla existe disponibilização de cadeiras anfíbias para permitir o banho de mar.

Tem-se também a dificuldade em relação à orientação no espaço. Mesmo com a Ilha das Cabras presente e atuante como um referencial, a homogeneidade da paisagem do entorno torna frequente situações em que usuários do espaço sentem-se perdidos, principalmente crianças e idosos.

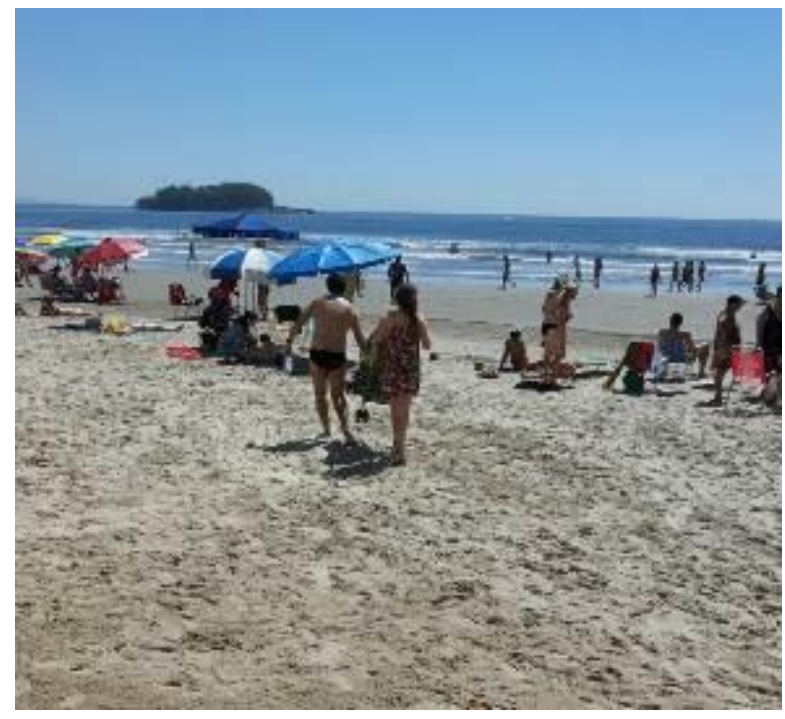

Imagem 09. Faixa de areia da zona balnear do Estudo de Caso. Fonte Acervo Próprio, 2013

Para minimizar estas dificuldades, propõe-se uma malha de esteiras a ser implantada em toda a orla, de modo que todos os usuários possam acessar com maior facilidade essa área que hoje não pode ser frequentada por alguns grupos. A extensão da mesma deve ser avaliada de acordo com as condições do substrato. Muitas vezes, trechos próximos ao mar possuem areia mais firme, dispensando o prolongamento das mesmas até a água. $16^{\circ}$ Ergodesign - Congresso Internacional de Ergonomia e Usabilidade de Interfaces Humano Tecnológica: Produto, Informações Ambientes Construídos e Transporte

$16^{\circ}$ USIHC - Congresso Internacional de Ergonomia e Usabilidade de Interfaces Humano Computador

CINAHPA | 2017 - Congresso Internacional de Ambientes Hipermídia para Aprendizagem.

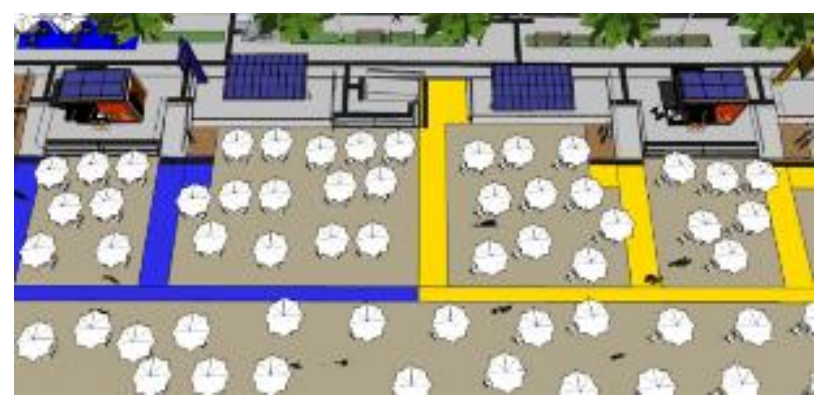

Imagem 10. Esteiras e zoneamento por cores proposto no Projeto Piloto da dissertação. Fonte Acervo Próprio, 2013

Além disso, recomenda-se que todo acesso formal da orla leve para uma esteira e cada região da praia possua uma cor distinta de esteira - facilitando a orientação e o deslocamento dos frequentadores. Além disso, a mudança de textura em relação à areia, assim como o contraste de cores, facilita a orientação de pessoas com baixa visão e cegueira.

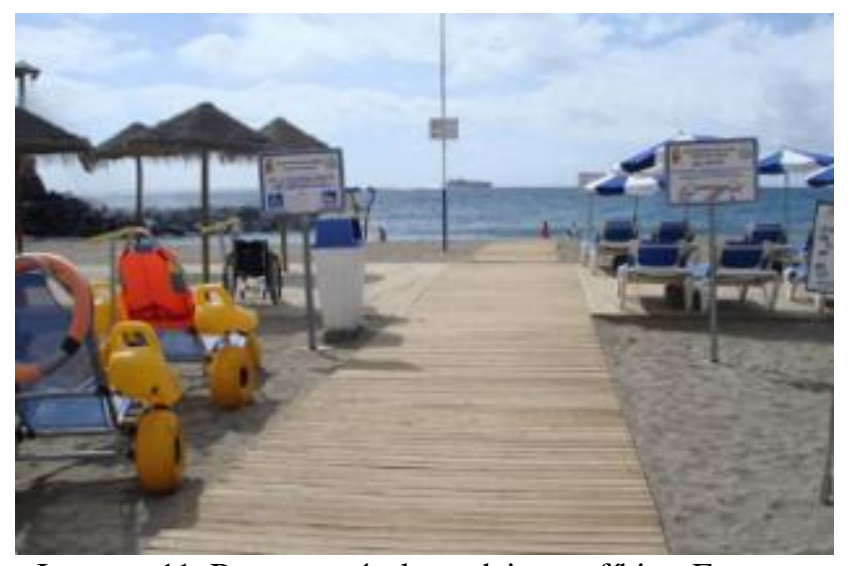

Imagem 11. Rota acessível e cadeiras anfíbias. Fonte: http://www.euroacessibilidade.com/images/fotos/grande _espanha.jpg

Deve-se ainda utilizar um material antiderrapante, regular e anti-reflexo em qualquer condição climática. O material usado não deve absorver calor com facilidade, como esteiras especiais para a praia, permitindo o deslocamento mais confortável de usuários sem calçados.

Sugere-se que a largura das esteiras sejam pensadas de acordo com o fluxo que cada porção da orla recebe. Esteiras largas, além de facilitadoras do deslocamento dos usuários 


\section{$16^{\circ}$ \\ ERGODESIGN USIHC CINAHPA}

também favorecem o deslocamento em dupla ou até trios, estimulando a comunicação no decorrer do trajeto. Não se recomenda o uso de esteiras com menos de $90 \mathrm{~cm}$ de largura.

A inclinação longitudinal da esteira, por sua vez, deve ser inferior a $8,33 \%$ enquanto a transversal inferior a $2 \%$, que deve sempre ser verificada devido a possibilidade de movimentação do terreno arenoso.

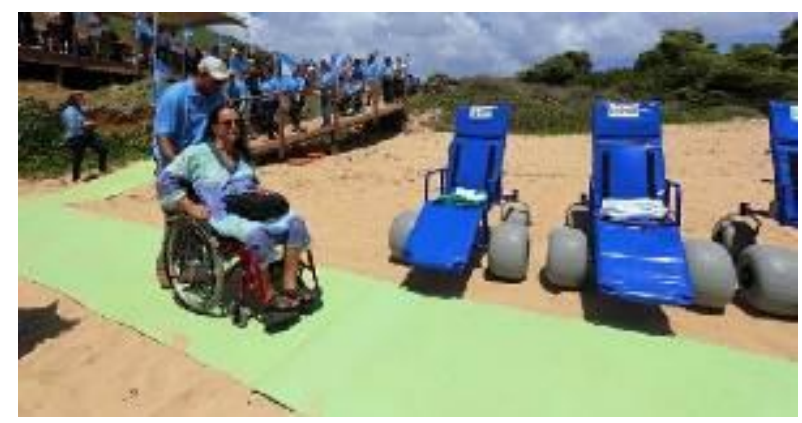

Imagem 12. Programa Praia sem Barreiras em Fernando de Noronha. Fonte: pessoascomdeficiencia.com.br/site/wpcontent/uploads/2013/02/fernando-de-noronhaacessibilidade.jpg

Além das estruturas permanentes, recomenda-se locais para a disponibilização de cadeiras anfíbias, espreguiçadeiras adaptadas, andadores resistentes à água e maresia, entre outros equipamentos que visam facilitar o uso deste espaço em conjunto com os demais elementos que envolvem o projeto acessível.

Esses locais devem ser sinalizados e distribuídos por toda a orla, preferencialmente próximo aos principais acessos.

\subsection{Uso das duchas e banheiros}

Duas atividades que ocorrem em paralelo às demais levantadas, baseadas em estruturas construídas pela Prefeitura Municipal, o uso das duchas e dos banheiros apresentam como principais problemas os descritos a seguir. Em relação à orientação as duchas não possuem marcação para localização das mesmas, as quais são distribuídas de forma heterogênea pela orla. Tem-se ainda o agravante de sua cor não oferecer contraste com o entorno, fazendo com que usuários tenham dificuldade em localizá-las. $16^{\circ}$ Ergodesign - Congresso Internacional de Ergonomia e Usabilidade de Interfaces Humano Tecnológica: Produto, Informações Ambientes Construídos e Transporte

$16^{\circ}$ USIHC - Congresso Internacional de Ergonomia e Usabilidade de Interfaces Humano Computador

CINAHPA | 2017 - Congresso Internacional de Ambientes Hipermídia para Aprendizagem.

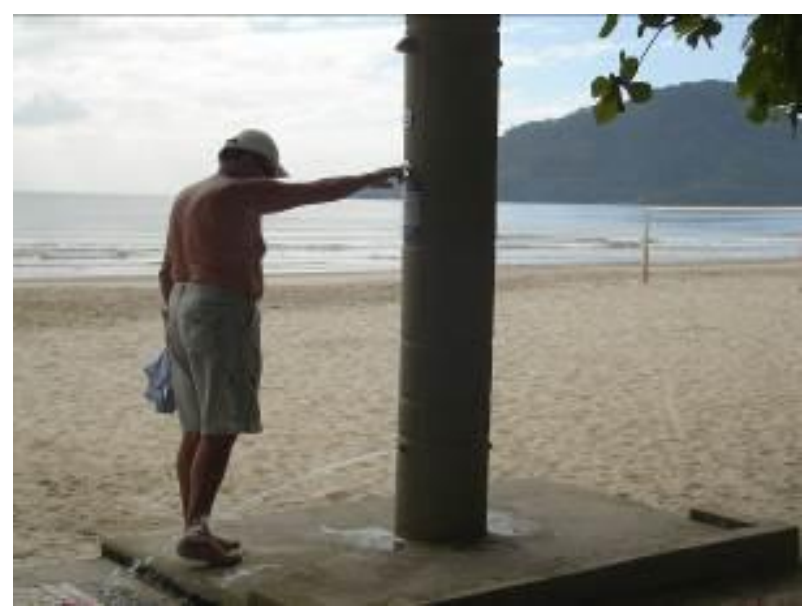

Imagem 13. Uso da ducha durante passeio acompanhado. Fonte Acervo Próprio, 2013

Quanto ao deslocamento, nas duchas não se verifica nenhum tipo de piso diferenciado que seja antiderrapante assim como toda a água da ducha não é escoada através de um ralo, mas escorre pela mesma rampa utilizada para seu acesso e ao calçadão, tornando-a escorregadia.

Outro problema verificado foi um degrau que chega a $10 \mathrm{~cm}$ para acesso da ducha a partir do calçadão, dificultando o fluxo das pessoas que finalizaram o uso deste equipamento. Do lado oposto, na borda entre ducha e areia, mesmo com um desnível significativo não há nenhum tipo de guarda corpo ou proteção. 


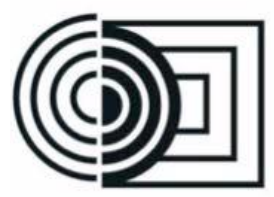

$16^{\circ}$ Ergodesign - Congresso Internacional de Ergonomia e Usabilidade de Interfaces Humano Tecnológica: Produto, Informações Ambientes Construídos e Transporte

$16^{\circ}$ USIHC - Congresso Internacional de Ergonomia e Usabilidade de Interfaces Humano Computador

CINAHPA | 2017 - Congresso Internacional de Ambientes Hipermídia para Aprendizagem.

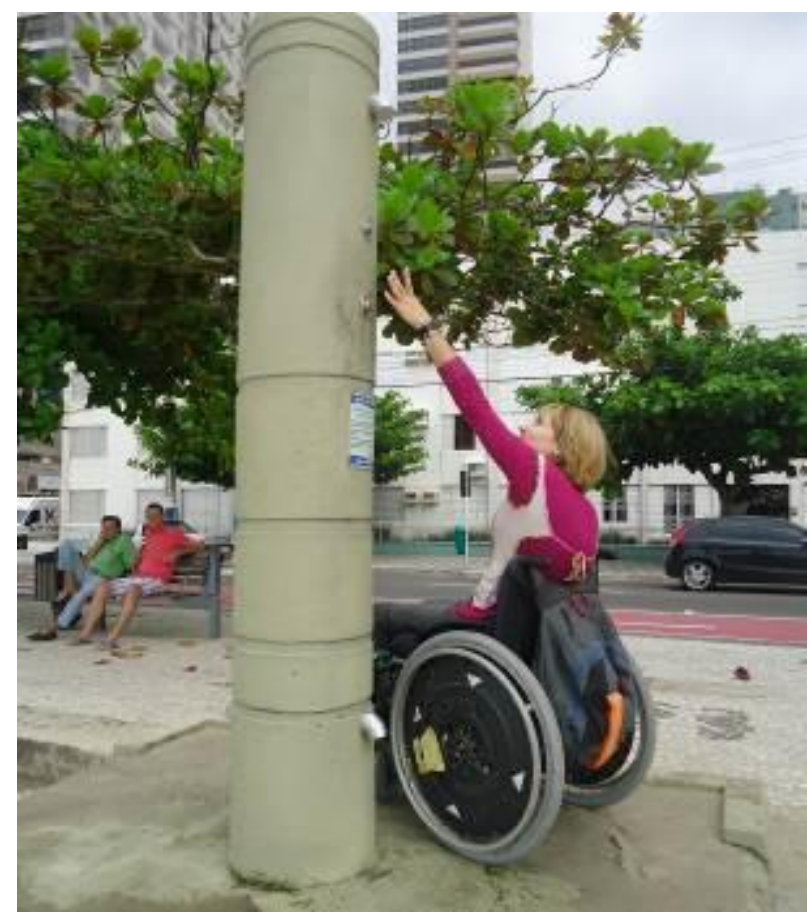

Imagem 14. Uso da ducha durante passeio acompanhado. Fonte Acervo Próprio, 2013

Além disso, ainda que se tenha a vantagem da divisão da ducha dos pés $\mathrm{x}$ ducha corporal, os comandos estão a 1,50 e a $1,70 \mathrm{~m}$ do piso, tornado $\mathrm{o}$ acionamento dificil para crianças, cadeirantes e usuários com restrição de movimentos nos membros superiores, como muitos idosos.

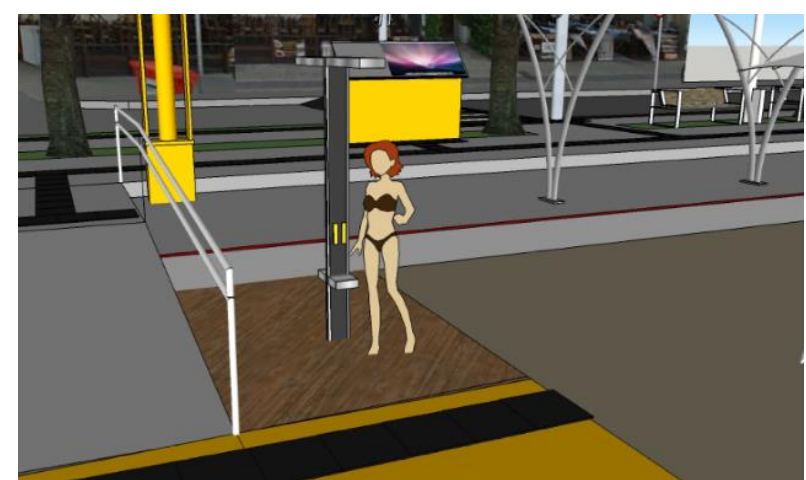

Imagem 15. Ducha proposta no projeto piloto da dissertação, com piso drenante, de cor e textura distinta ao entorno. Fonte Acervo Próprio, 2013

Por outro lado, o acionamento da água é de fácil manuseio, por ser apenas um botão de leve pressão.

Pensando no acesso e uso seguro à área da ducha, sugere-se que seja aplicada sinalização tátil de alerta para demarcar a mudança da área adjacente para a área molhada, com piso drenante, estável e antiderrapante.

Além disso, a mudança de textura em relação ao entorno, assim como o contraste de cores, facilita a orientação de deficientes visuais.

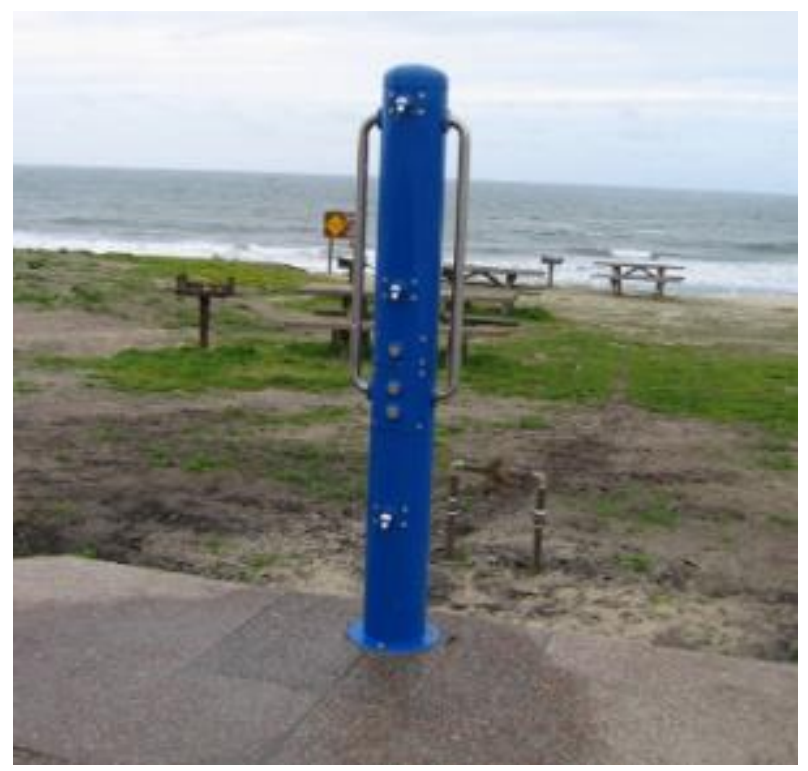

Imagem 16. Modelo de ducha para zonas balneares. Fonte:

http://www.euroacessibilidade.com/images/fotos/grande _espanha.jpg

Pensando no fluxo de seu uso, de modo que pessoas em espera não se tornem uma barreia àqueles que ainda utilizarão o equipamento recomenda-se que sua implantação tenha sinalização do fluxo recomendado, seja ela por cores ou texturas distintas.

Sugere-se ainda que os botões de acionamento sejam divididos para lava-pés e ducha ou se utilize equipamentos distintos para cada fim.

Altura recomendada para lava pés é de $80 \mathrm{~cm}$ e para ducha de $1,20 \mathrm{~m}$ a partir do piso. Esta medida, além de sustentável por permitir economia de água, proporciona ao usuário a escolha da melhor alternativa para o uso. De acordo com a geometria do equipamento, a incorporação de barras de apoio facilitam o uso e o equilíbrio.

Os banheiros, por sua vez, sempre anexos aos quiosques, possuem o mesmo problema de reconhecimento, ainda que tenham boa distribuição na orla.
Realização:
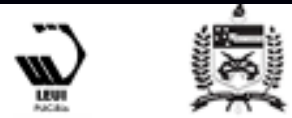


\section{$16^{\circ}$ \\ ERGODESIGN USIHC CINAHPA}

No interior, a falta de contraste entre os planos de piso, parede e forro dificulta a orientação dos usuários com baixa visão.

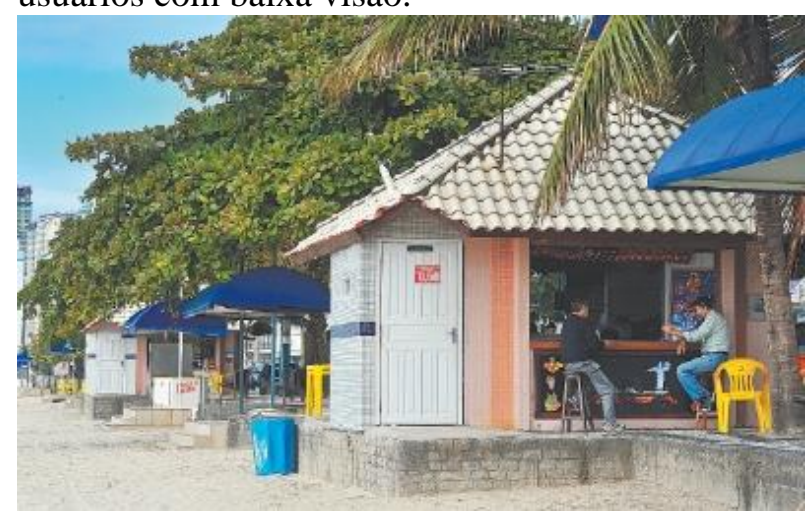

Imagem 17. Quiosque com banheiro anexo. Fonte Acervo Próprio, 2012

É frequente observarmos problemas de deslocamento devido ao depósito de materiais ou equipamentos que atrapalham o fluxo interno, configurando uma barreira atitudinal devido à falta de informação sobre a necessidade de áreas desobstruídas para transferência e giro de um usuário de cadeiras de rodas. Além disso, o acesso a este equipamento é lateral e frequentemente sem espaço para giro de cadeiras de rodas.

Uma facilidade verificada é seu posicionamento entre calçadão e praia, permitindo o uso por frequentadores de ambos os espaços. $16^{\circ}$ Ergodesign - Congresso Internacional de Ergonomia e Usabilidade de Interfaces Humano Tecnológica: Produto, Informações Ambientes Construídos e Transporte

$16^{\circ}$ USIHC - Congresso Internacional de Ergonomia e Usabilidade de Interfaces Humano Computador

CINAHPA | 2017 - Congresso Internacional de Ambientes Hipermídia para Aprendizagem.

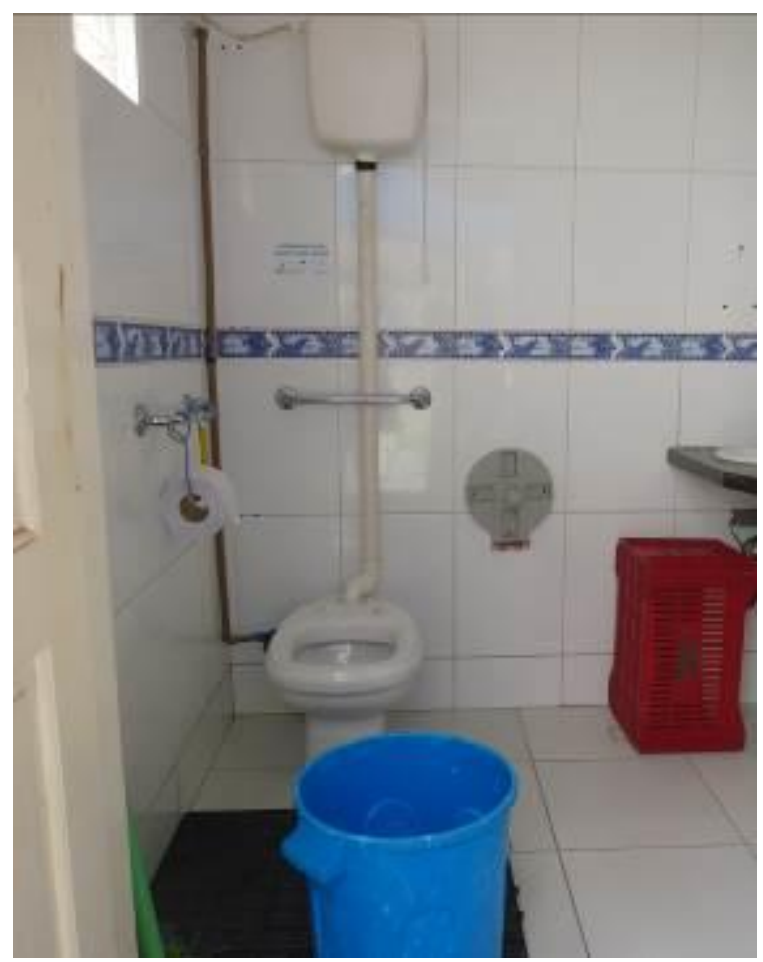

Imagem 18. Banheiro quiosque. Fonte Acervo Próprio, 2013.

Em relação ao uso, os banheiros são "semipúblicos" - na maioria dos quiosques é necessário pegar uma chave e até pagar para utilizar o banheiro, o que restringe o acesso e uso facilitado de todos, sendo também uma barreira atitudinal. Soma-se a este problema o não atendimento de itens estabelecidos na NBR9050/2015 como: as barras de apoio, espelhos e equipamentos instalados de forma inadequada e/ou inexistentes. Por fim, analisando a comunicação, não existe sinalização em Braille tampouco comunicação em outras línguas ou símbolos para localizar este equipamento. 


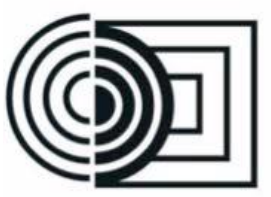

$16^{\circ}$ Ergodesign - Congresso Internacional de Ergonomia e Usabilidade de Interfaces Humano Tecnológica: Produto, Informações Ambientes Construídos e Transporte

$16^{\circ}$ USIHC - Congresso Internacional de Ergonomia e Usabilidade de Interfaces Humano Computador

CINAHPA | 2017 - Congresso Internacional de Ambientes Hipermídia para Aprendizagem.

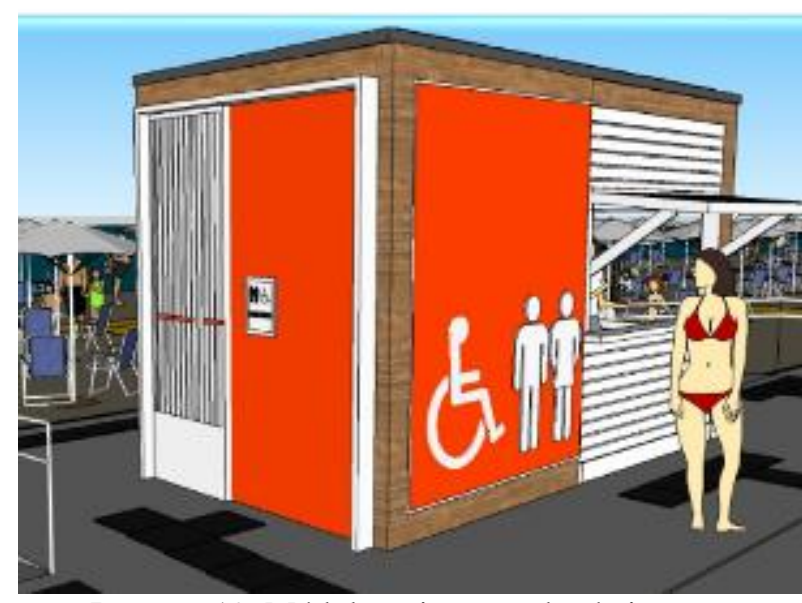

Imagem 19. Módulo quiosque x banheiro com sinalização por pictogramas e placa do Projeto Piloto. Fonte: Elaborado pela autora, 2012.

Para otimizar a orientação dos usuários quanto ao posicionamento dos sanitários na extensão da orla, recomenda-se que a informação esteja visível a todos, usando mais de uma opção de linguagem (tátil, pictórica, Braille).

Informações a respeito do banheiro devem ser colocadas tanto na porta quanto em sua lateral, de modo a permitir a leitura mesmo que a porta esteja aberta.

Além disso, deve-se ater que a sinalização tátil direcional e de alerta deve levar o usuário da rota acessível principal até o banheiro. A configuração desta rota deve seguir o determinado pela NBR9050/2015.

Outro detalhe interessante seria adotar contraste entre cor da fachada e piso e de porta de entrada em relação à fachada, para permitir o fácil reconhecimento do acesso àqueles que possuem baixa visão.

Em frente à porta deve-se considerar área de giro com diâmetro de $1,60 \mathrm{~m}$ livre de barreiras, permitindo o deslocamento e correta movimentação de um usuário cadeirante ou mesmo usuarios com carrinho de bebê, por exemplo.

A porta do banheiro acessível deve possuir ainda abertura para fora ou de correr - vão de no mínimo $80 \mathrm{~cm}$ e a maçaneta deverá ser no formato de alavanca.

Para portas de giro, uma barra interna posicionada de acordo com NBR9050/2015 e área com revestimento resistente na parte inferior também são imprescindíveis.
Em relação aos revestimentos, ainda que os sanitários sejam áreas internas, sugere-se o uso de pisos antiderrapantes, uma vez que é comum banhistas fazerem uso desta estrutura e escorregões podem ocorrer caso o piso seja inadequado. Para os demais itens do projeto de interiores dos sanitários acessíveis, soluções possíveis são encontradas na NBR9050/2015.
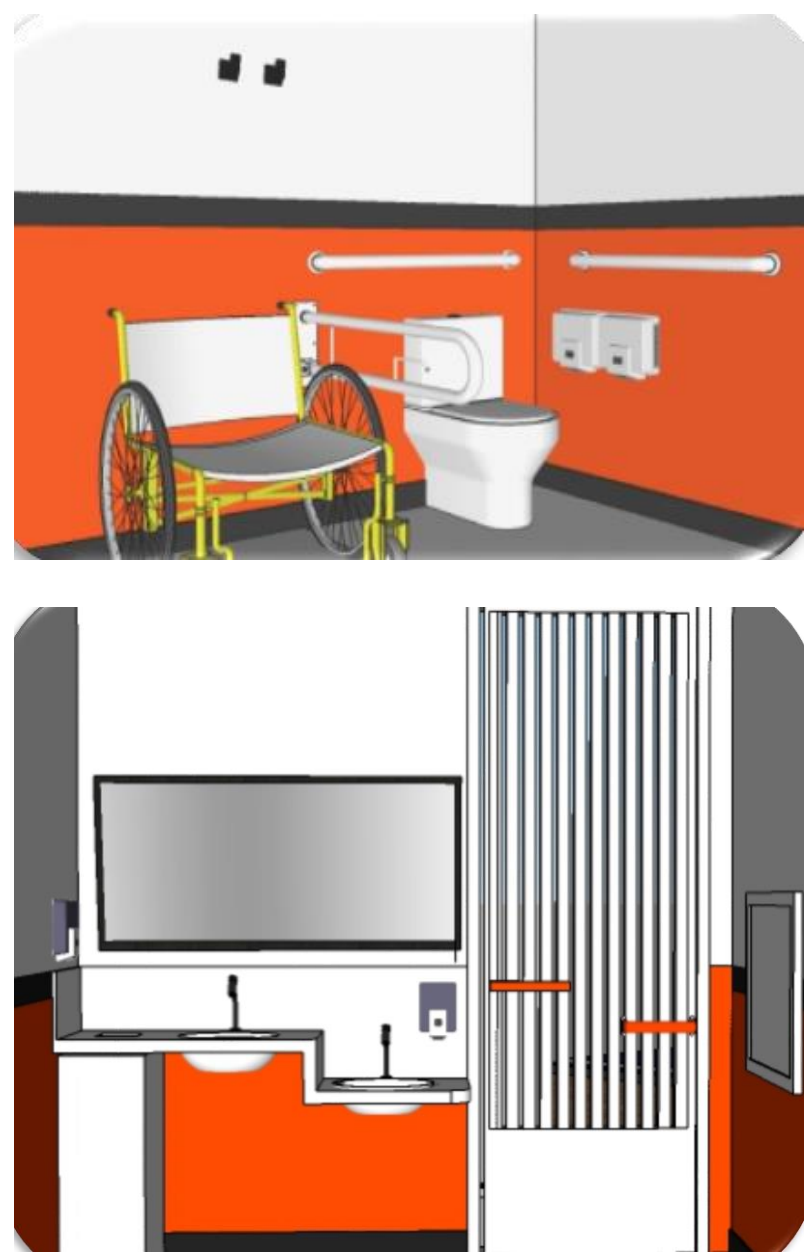

Imagem 20. Interior de banheiro acessível proposto no Projeto Piloto. Destaque para contraste entre planos de piso e parede, assim como entre equipamentos e alvenaria. Fonte: Elaborado pela autora, 2013.

Cabe ressaltar que cada projeto possui uma geometria específica o que gera a necessidade de análise, caso a caso, para que se faça uma adaptação da norma de acordo com cada situação encontrada.
Realização:
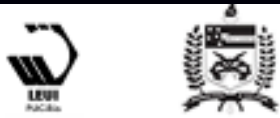


\section{$16^{\circ}$ \\ ERGODESIGN USIHC CINAHPA}

$16^{\circ}$ Ergodesign - Congresso Internacional de Ergonomia e Usabilidade de Interfaces Humano Tecnológica: Produto, Informações Ambientes Construídos e Transporte

$16^{\circ}$ USIHC - Congresso Internacional de Ergonomia e Usabilidade de Interfaces Humano Computador

CINAHPA | 2017 - Congresso Internacional de Ambientes Hipermídia para Aprendizagem.

\section{Considerações finais}

Antes de qualquer elaboração de um projeto de acessibilidade é de fundamental importância conhecer o local que este será implantado e suas barreiras, seus usuários e deficiências, assim como as atividades a serem realizadas. Estes dados são indispensáveis para a criação de espaços inclusivos à maior gama possível de pessoas, independentemente de suas características individuais.

Durante a elaboração das soluções devem-se considerar todas as etapas pelas quais o usuário deverá passar até a realização da atividade final. Um exemplo prático disso é de que nada vale se pensar em uma faixa de areia acessível caso o usuário não consiga antes, chegar até ela, seja devido a falta de transporte adaptado, vagas acessíveis ou ainda um desnível sem solução adequada.

Deve-se estar consciente também, durante um projeto, seja ele novo ou de adaptação, que nem sempre é possível solucionar um problema apenas resolvendo as condicionantes da escala local. Nestes casos é necessário ampliar a escala e contextualizar a solução além do espaço que está sendo criado ou redesenhado.

Além disso, a solução de problemas de acessibilidade não se encerra no projeto. Após esta etapa há ainda a execução e a fiscalização, durante as quais devem ser mantidas e exigidas as recomendações e propostas na primeira etapa.

Recomenda-se que, desde o estudo preliminar até a entrega da execução, tenha-se sempre um profissional habilitado para acompanhamento e instrução da mão-de-obra tratando-se da correta execução dos itens propostos.

Cabe ressaltar ainda que o aprofundamento técnico sobre acessibilidade, o empenho de administradores públicos e considerável vontade política são aspectos extrínsecos ao projeto, todavia fundamentais para o sucesso de sua implantação.

Por fim, dado que a estrutura de uma praia pode ser muito diferente de uma para a outra, não é possível oferecer o mesmo grau de acessibilidade para todos. Portanto, informações claras devem ser fornecidas sobre o estado de cada praia e os serviços que presta, e isso deve ser postado tanto nos pontos de acesso à praia em si como em outras fontes de informação pública. Desta forma, as pessoas podem escolher antecipadamente quais praia que eles querem - e são capazes - de visitar.

\section{Bibliografia}

\section{ASSOCIAÇÃO BRASILEIRA DE NORMAS} TÉCNICAS. NBR 9050: Acessibilidade de Pessoas Portadoras de Deficiência a Edificações, Espaço, Mobiliário e Equipamento Urbano. Rio de Janeiro: ABNT, 2015.

DIOGO, M.J.D. Consulta de enfermagem em gerontologia. In: PAPALÉO NETTO, M. (Coord). Gerontologia: a velhice e o envelhecimento em visão globalizada. São Paulo: Atheneu, 1999.

DISCHINGER, Marta. Designing for all senses: accessible spaces for visually impaired citizens. Göteborg: Chalmers University of Technology, 2000.

DISCHINGER, M.; BINS ELY, V. H. M. Promovendo acessibilidade nos edifícios públicos: Guia de avaliação e implementação de normas técnicas. Santa Catarina: Ministério Público do Estado, 2005.

; PIARDI, Sonia Maria Demeda Groisman. Promovendo acessibilidade espacial nos edifícios públicos: programa de acessibilidade às pessoas com deficiência ou mobilidade reduzida nas edificações de uso público. Florianópolis, 2011.

FROMER, B; VIEIRA, D.D. Turismo e terceira idade. São Paulo: Aleph, 2003.

QUIVY, Raymond e CAMPENHOUDT, Luc Van, Manual de Investigação em Ciências Sociais. Lisboa: Gradiva, 2003.

\section{SCHÖN, D A. Educating the reflective}

Realização:

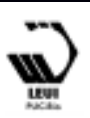




\section{$16^{\circ}$}

ERGODESIGN USIHC CINAHPA $16^{\circ}$ Ergodesign - Congresso Internacional de Ergonomia e Usabilidade de Interfaces Humano Tecnológica: Produto, Informações Ambientes Construídos e Transporte

$16^{\circ}$ USIHC - Congresso Internacional de Ergonomia e Usabilidade de Interfaces Humano Computador

CINAHPA | 2017 - Congresso Internacional de Ambientes Hipermídia para Aprendizagem.

practitioner; Donald Schön's presentation to the 1987 meeting of the American Educational Research Association. Washington, DC, 1987. Disponível em:

$<$ http://educ.queensu.ca/ russellt/howteach/schon8 7.htm.> Acesso em: 29/06/2014.

WORLD TOURISM ORGANIZATION (WTO). Aprobación del código ético mundial para el turismo. (Chile, 1999). Disponível em: $<$ http://world-tourism.org./presrel/code_R.htm >. Acesso em: 06/05/2010. 